\title{
Smart Climate Resilient and Efficient Integrated Waste to Clean Energy System in a Developing Country: Industry 4.0
}

\author{
Anthony Njuguna Matheri, Belaid Mohamed, and \\ Jane Catherine Ngila
}

\section{Contents}

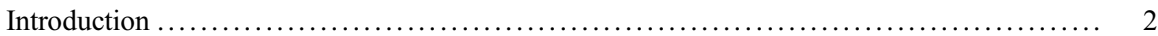

Paris Agreement on Climate Change ...................................... 3

Climate-Land-Water-Energy-Food Nexus ...................................... 4

Energy Security and Pursuit of Water, Food, and Earth System Resilience ............. 6

Water Security and Pursuit of Energy, Food, and Earth System Resilience ............. 9

Food Security and Pursuit of Water, Energy, and Earth System Resilience ............. 10

Biophysical and Biogeochemical Land-Climate Systems ........................ 11

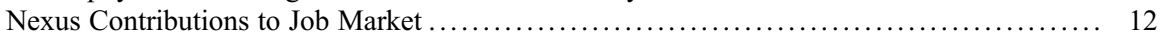

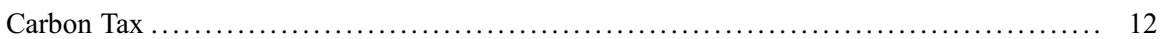

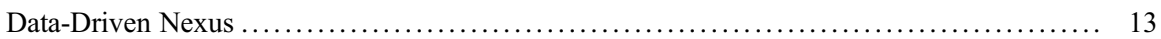

Industry 4.0 in Nexus and Climate Resilient ............................... 13

Modelling of the Water-Energy-Food-Land-Climate Nexus ....................... 14

Adaptation of Climate Change Technology Transfer in Developing Countries ............. 16

Nexus and Research Gap ................................................... 17

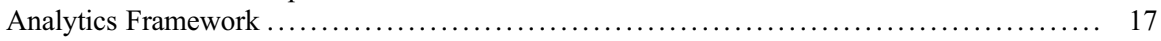

Nexus Securities and Environmental Protection ................................ 20

Policy and Governance (Coordination and Collaboration) for Climate Change ............ 21

This chapter was previously published non-open access with exclusive rights reserved by the Publisher. It has been changed retrospectively to open access under a CC BY 4.0 license and the copyright holder is "The Author(s)". For further details, please see the license information at the end of the chapter.

\footnotetext{
A. N. Matheri $(\bowtie) \cdot$ B. Mohamed

Department of Chemical Engineering, University of Johannesburg, Johannesburg, South Africa e-mail: mbelaid@uj.ac.za

J. C. Ngila

Department of Chemical Science, University of Johannesburg, Johannesburg, South Africa

Academic Affair, Riara University, Nairobi, Kenya

e-mail: jcngila@riarauniversity.ac.ke
} 


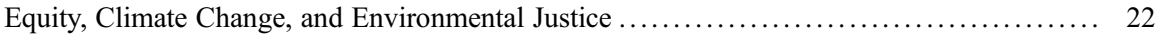

Conclusion and Recommendations ........................................... 24

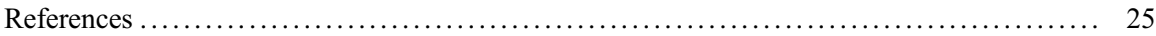

\section{Abstract}

Climate change impacts a natural and human system on the entire globe. Climaterelated extreme weather such as drought, floods, and heat waves alters the ecosystems that society depends on. Climate, land, energy, and water systems (CLEWS) are a critical aspect of high importance on resource availability, distribution, and interconnection. The nexus provides a set of guidelines to South Africa that aims on creating a level playing field for all sectors while achieving the aims of the SDGs that are cross-sectoral and multilevel approaches to climate change. The nexus expressed three domains that included resources, governance, and security. It integrated a smart climate resilient with inclusion of the governance and involvement of the stakeholders. Recognition of spatial and sector interdependencies should inform policies, investment and institutional for enhancing nexus security and climate change towards making transition green carbon deals. The nexus offers an integrated approach that analyzes the trade-offs and synergies between the different sectors in order to maximize the efficiency of using the resources that adapt institutional and optimum policy arrangements. Economic transformation and creation of employment through green economy is one of the COP26 green deal agendas in curbing the carbon emissions (green house emission, industrial processes, fuel combustion, and fugitive emissions) as mitigation to climate change, which is cost-effective and economically efficient. The future climate change policy in the developing countries is likely to be both promoted by climate technology transfer and public-private cooperation (crosssector partnership) through the technology mechanism of the nexus and inclusion of the gender.

\section{Keywords}

Adaptation $\cdot$ CLEWS $\cdot$ Climate change $\cdot$ Climate technology $\cdot$ Ecosystem $\cdot$ Green economy $\cdot$ Policy $\cdot$ Resilience $\cdot$ SDGs $\cdot$ Nexus

\section{Introduction}

Green revolution, disruption of the natural resources and social-economic impact are becoming increasingly in Industry 4.0 (Fourth Industrial Revolution-41R). The is due to enhancement of the adaptive capacity for the complex global challenges in advanced nexus approach to the sustainable management of climate change, land use, water, energy, and food. This serve the paradigmatically that was isolated and understanding of the interrelation of the WEF, human well-being, resilient ecosystem, climate change that coexists within the planetary boundaries. The shift in society disruption legion of unfortunate solution to an environment or development 
challenges that end up creating new, unforeseen problems and dilemma (Newell et al. 2019; Matheri et al. 2020). The nexus describes the interconnections and interdependencies between the land, water, energy, and food (LWEF) sectors. These interdependencies of the LWEF securities have received growing attention in the past years by researchers and policy-makers. Lack of understanding of the nexus has been described as a major global economic challenge by the World Economic Forum. This put forward the nexus approach as a fundamental shift for sustainable development (Hassan et al. 2018). A review on the LWEF and land utilization needs to be addressed on policy-making and decision-making concerning the nexus framework and climate change. This bridges the gap between science and policy in the implementation of nexus. More importantly, the nexus can also support achieving the United Nations Sustainable Development Goals (SDGs), 2030 Agenda, because of its close relation to three SDGs: SDG2 "zero hunger," SDG6 "clean water and sanitation for all," SDG7 "affordable and clean energy," and SDG13 "climate action" (Tashtoush et al. 2012).

The nexus is expressed into three domains that include resources, governance, and security. The domain requires inclusion of the policy and institution expertise, natural resources use, environmental science, and engineering expertise for the mutual perspective of multiple decision-making, solution, and resource recovery (Scott et al. 2015, 2018). The priorities areas for climate change include decarbonization of the economy, digitization, decentralization of the production, transition of $100 \%$ renewable energy, carbon taxation (tax the polluters not people), access to sustainable finance, assist small island and least developing countries, support people affected by climate change, increase accessibility and availability of the jobs and livelihood, nature-based solutions, stronger commitments by the major emitters, and commitments to achieve carbon neutrality by 2050 (United Nation (UN) 2020). The focus is placed on implementation of the nexus concepts with a smart climate resilient on nexus regional dialogue programs by United Nations (UN) bodies, World Bank, GIZ, European Union (EU), Africa Union (AU), Middle East and North Africa (MENA), and World Economic Forum among others.

\section{Paris Agreement on Climate Change}

Climate change results in disruption of national economies that affect the countries, communities, living standards, and flora and fauna. With likely shift of the climate zones, long-term, changes of the rainfall patterns, and raising of the temperature, climate change shock is expected to increase frequency putting pressure in energy, food, water supply, and competition of land ownership in unaffected areas (Stocker et al. 2013; Carter and Gulati 2014). The historic Paris agreement provides countries with strong global climate change response by keeping the temperature rise below 2 $1.5^{\circ} \mathrm{C}$. It encourages parties and stakeholders to reduce the impacts of the climate change (ambition and implementation to ensure highest mitigation and adaptation efforts by all parties with building climate resilience).

The intergovernmental climate change panels have recorded the following: 
- 1901-2010: Warm oceans and diminishing snows and ice by 1.07 million $\mathrm{km}^{2}$ with rise of the sea levels by $19 \mathrm{~cm}$

- 1880-2012: Increase of the temperature by $0.85{ }^{\circ} \mathrm{C}$ due to warmer climate

- 1990 to date: Global emission of the $\mathrm{CO}_{2}$ that has increased by $50 \%$

The agreement solidifies international cooperation on investment of a low-emission economy (green economy) that contains transparency framework, mutual trust, and confidence. Industry 4.0 is overseeing the scalable, affordable solutions that are more resilient to the economy and mostly helping the developing countries toward the low-carbon economy. Major technologies and institutions will see a shift of containing and ensuring that global warming does not exceed the threshold. SDG 13 defines the commitment by strengthening resilience and adaptive capacity; integrating climate change strategies, policies, and planning; creating awareness on adaptation, mitigation, and impact reduction; and implementing meaningful mitigation again and transparency through UNFCCC (United Nation Framework Convention on Climate Change) framework and inclusion of the marginalized communities and planning and management (SDGs, UN 2019). The impact of the climate change will be amplified through interdependence and interconnection among the resources, land, water, energy, and food.

\section{Climate-Land-Water-Energy-Food Nexus}

The global web of mutual interlinkages defines the climate-land-water-energy-food nexus on societal changes that drive growth and demand. The ongoing disruption of the environment is likely to alter the accessibility or availability of land, energy, water, and food that is central to climate change policies and natural resource management (Markantonis et al. 2019). Holistic and integrated approaches to resource planning and management have been largely embraced by decision-makers and stakeholders although the benefits of the nexus approach may appear obvious to its advocates. The nexus is related to integrated management, consumption, economic resources, policy, security, and approach. The nexus concept needs to be approached beyond the research and development domain.

The WEF nexus has emerged as a useful disruption in Industry 4.0 in understanding multiple interdependencies that coexist between land use, water, energy, food, and climate change. It is a multidisciplinary that cuts across both state and nonstate sectors. The WEF has potential to unlock groundbreaking solutions to complex problems with appropriate models and climate change mitigation. The is expressed as National Development Plans (NDP) and United Nations Sustainable Development Goals (SDG) that are emerging in the international agenda at the World Economic Forum on understanding the link between use of resources in providing universal basic rights and climate protection (Seeliger et al. 2018). This was welcomed by the Conference of Parties (COP) by the UNFCCC on enhancement of climate technologies' development and knowledge transfer through the technology mechanisms of greater public-private cooperation (cross-sector partnerships). This is 


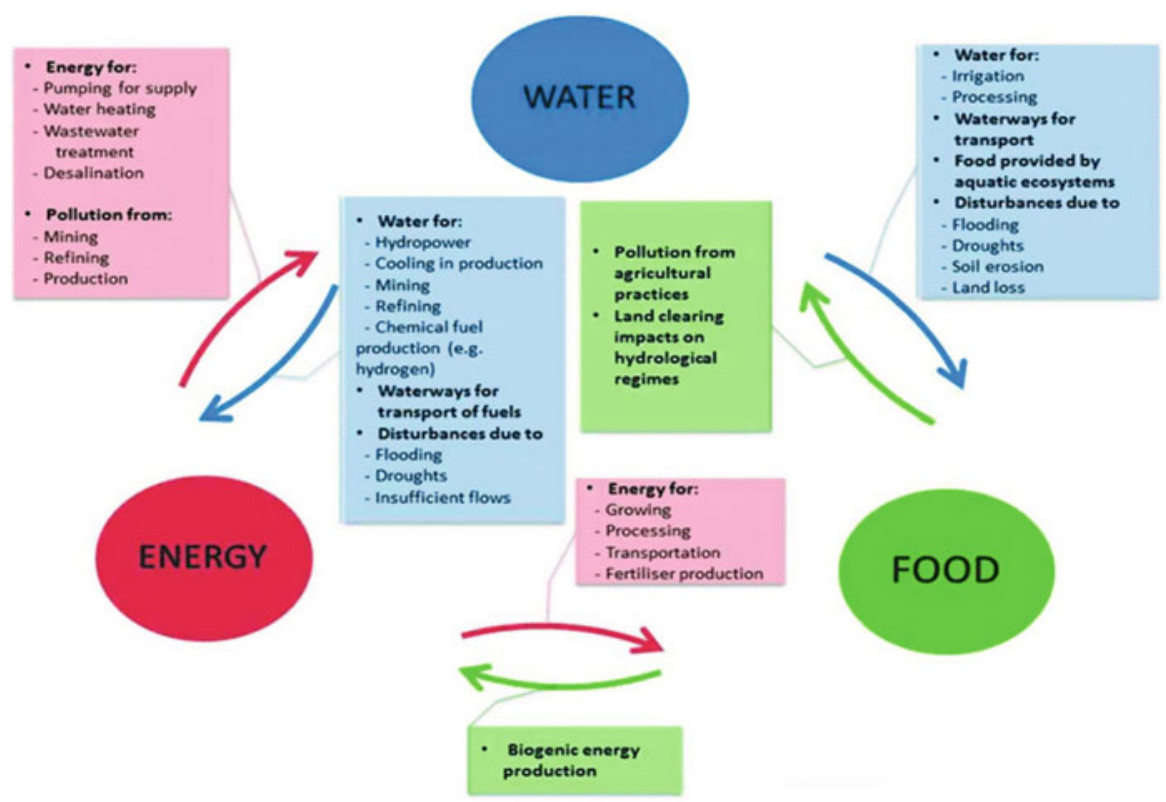

Fig. 1 The water-energy-food nexus concept. Source: IW: LEARN, Germany 2014

through the action on climate and SDGs, climate technology, education, youth, gender, having open-source information and intellectual properties, climate finance, adaptation and resilience, and capacity building (Forsyth 2007; Forsyth 2005; COP25 2019a, b). Figure 1 shows the WEF nexus concept.

The nexus can provide technology, innovation, and analytical framework by complementing design principles and new policy perspectives for the CLEWS' security policy. Building future planned actions on nexus needs advanced research and development (R\&D) such as cost action and Horizon 2020. The role of the WEF nexus is gaining increasing attention in the region from developing countries, which is a partner in the Nexus Regional Dialogues Programme (NRDP) with an aim to create an enabling environment that drives implementation and cross-sectoral engagement of nexus investment projects. The intention is to provide decisionmakers with prospects where the theory of the nexus concept has been made operational.

The C40 cities program seeks to build and identify opportunities and build evidence benefits of climate action synergies within the climate, water, and energy nexus. C40 cities have built a platform of networks, adaptation, communications, finance, and other programs on taking bold climate actions that are healthier and more sustainable to resilient cities (C40 2020).

Specific to Agenda 2030, 4 of the 17 SDGs are directly related to the food, water, and energy sectors (Tashtoush et al. 2012; United Nation (UN) 2015): 
- SDG 2 (Zero Hunger): End hunger, achieve improved nutrition and food security, and promote sustainable agriculture.

- SDG 6 (Clean Water and Sanitation): Ensure availability and sustainable management of sanitation and water for all.

- SDG 7 (Affordable and Clean Energy): Ensure access to reliable, affordable, sustainable, and modern energy for all.

- SDG 13 (Climate Action): Taking action to combat climate change and the impacts.

Although these four goals directly relate to the individual areas of climate change, water, energy, and food security, progress in 12 of the 17 SDGs is directly related to the sustainable use of resources. Some goals cannot be achieved without a holistic view of the nexus.

\section{Energy Security and Pursuit of Water, Food, and Earth System Resilience}

Energy security exists where there is uninterrupted availability of energy sources and distribution at an affordable price to the consumers. With frequent power rationing (load shedding) in many African countries that ranges in hours, this remains a dream in achieving adequate energy production, stable tariffs, relax policies on independent power production (IPP), political stability, intelligent distribution of energy, green buildings, smart metering, energy auction, bidding and pricing, self-driving cars, electronic cars, energy storage, smart cars, high-speed trains, next-generation GPS devices, autonomous vehicles, gyroscopic vehicles, smart roads, hyperloops, micromobility, intelligent electric vehicle networks, etc. All of this lies on policies and politics.

The food challenges from energy perspectives include increasing food cooling systems; energy-intensive farm operations; local food chains that is minimizing transport energy; extended crop seasons; artificial intelligence and blockchain technology on food tracking systems; use of remote sensing technology (i.e., drone use for mapping, irrigation, and spraying) to monitor food production, spraying and irrigation; use of hydroponic and aeroponics for urban farming; use of drone to monitor crop production and pest controls; use of robotics technology in farming; and use of artificial intelligence in detecting crop diseases at an early state which all needs intensive use of energy and technology literacy.

The water challenges from energy perspectives include energy intensive of desalination, water reuse, rising demand for carbon-free energy systems, climate change raises water needs of energy, water allocation to energy generation, water capture from atmosphere (humid ambient air) using solar-powered devices, and decentralized wastewater treatment (online wastewater treatment and monitoring using sensors).

The future of transportation lies on our behavior, culture, taboos, and way of life. How often one drives the vehicles, the mode of transport we take, the types of fuels 


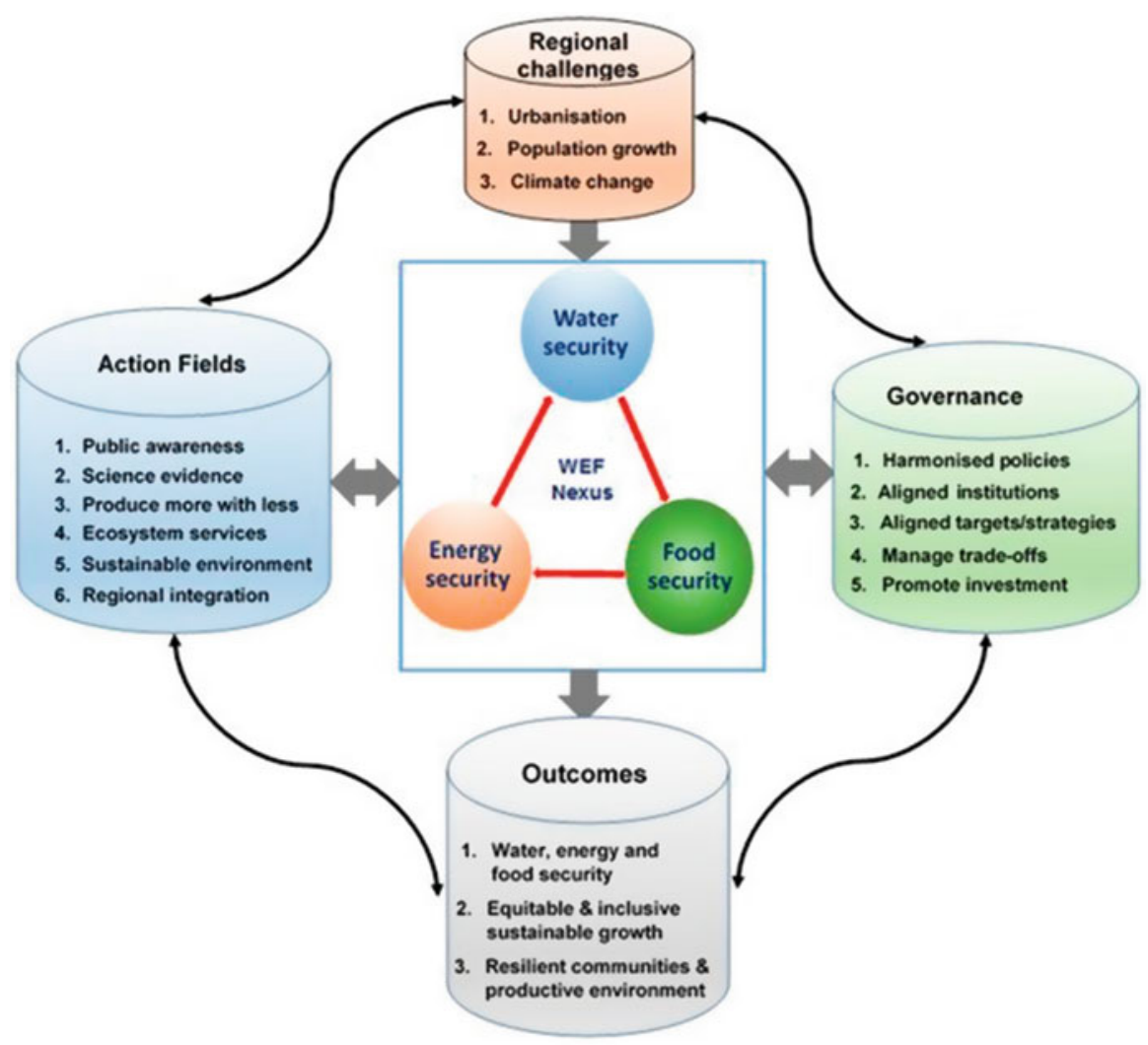

Fig. 2 Conceptual framework of the regional water-energy-food nexus action plan

we use, an investment in public transportation, compensation due to shift and investment on green energy (green funding), congestion charges, and more vehicle-pooling and ride-hailing services justify dependence toward zero emission and thus mitigation to climate change. Figure 2 shows the conceptual framework of the water-energy-food action plan (Nhamo et al. 2018; Chirisa and Bandauko 2015).

\section{Reliable Integrated Waste Management and Nexus}

The populace development, urbanization, economic advancement, and improvement in expectations for everyday comforts in disruption of Industry 4.0 (4IR) have increased the amount of the waste generation in the cities and reintroduction of the emerging contaminants into waste streams. These wastes pose sanitary, health hazard, and environmental risks. These contaminants end up in water bodies and landfills, prompting to pollution of the entire environment, thus putting a high strain on social, economic, health sector, and climate change. Tackling integrated waste management disruption and energy security requires stipulated regulation and policies that coordinate waste administration frameworks. The future of digital disruption and transformation of industrial platform, energy-water-food generation lies on 
the decarbonation, decentralization, electrification, and digitalization (sustainable industrialization and diversification in the digital era). Technologies in the era of digital transformation are becoming commercially viable to the integrated systems and services that enable sustainable management and efficient integrated waste management (IWM), energy production, and use. Reliable IWM and data provide an all-inclusive resource for a critical, comprehensive, and informative evaluation of IWM options in all integrated waste management programs. Optimized programmed operations using predictive analytics (i.e., convectional and AI modelling), big data, blockchain, e-citizens, fintech, and data mining are the fundamental apparatuses generally used to assess the policy impact and technology of savvy arrangements, just as to design the most ideal approaches to move from current to more intelligent urban areas. There are several obstacles confronting municipal solid waste management within the cities. Some of such obstacles are interrelation of urbanization and economic growth; change of living standards that causes complexity of the waste stream; overstretching of the superannuated infrastructure; lack of location and facilities to expedite waste separation at source; Intelligent Network Infrastructure (tracking collectors, IoT bins, automated recycler with incentive to users, available recycle plants); and integrated waste management technologies that are handy and costly compared to landfilling and composting. Detachment of waste at the source and embracing zero waste financial motivation urge a family to diminish squander.

The organic waste can be changed over to vitality utilizing waste to vitality elective courses that incorporate transformation, gasification, combustion, pyrolysis and liquefaction, organic procedures, aging, hydrolysis, and anaerobic assimilation for biogas and biomethane creation. An investigation waste quantification to assess the sustainability, characterization to assess the composition, and anaerobic digestion to assess the amount and quality of energy $\left(\mathrm{CH}_{4}\right)$ generated by the City of Johannesburg were carried by a team of researchers (University of Johannesburg). The outcomes indicated that 1,444,772 tons per annum of local waste were created in the city of six million residents consistently as announced by the City of Johannesburg (CoJ), South Africa Pikitup (2017). Littering alone costs the city 5.7 million dollars every year, while illicit dumping costs another 6.2 million dollars for each annum. Organic waste can be changed over to vitality utilizing waste or vitality elective courses that incorporate transformation, gasification, combustion, pyrolysis and liquefaction, organic procedures, aging, hydrolysis, fermentation, and anaerobic assimilation for biogas and biomethane creation. Recyclable squander (paper/paperboards, plastics, and glass) was the second biggest part $12 \%, 19 \%$, and $9 \%$, respectively (Matheri et al. 2018a, b; Matheri 2016, 2020; Fig. 3).

The generated biomasses had potential of the alternative clean fuel production to meet the energy security and climate change mitigation. The physiochemical properties of the biomass showed the energy value equivalent to natural gas. The generated energy will contribute to a reliable, affordable, carbon-neutral, sustainable form of modern energy. This will help in the development of the conservation of biodiversity, waste management, poverty eradication, and adequate waste to energy recovery management strategies and improve living standards of the citizens (Matheri 2016). The energy system disruption will assist to bridge the gap in the 


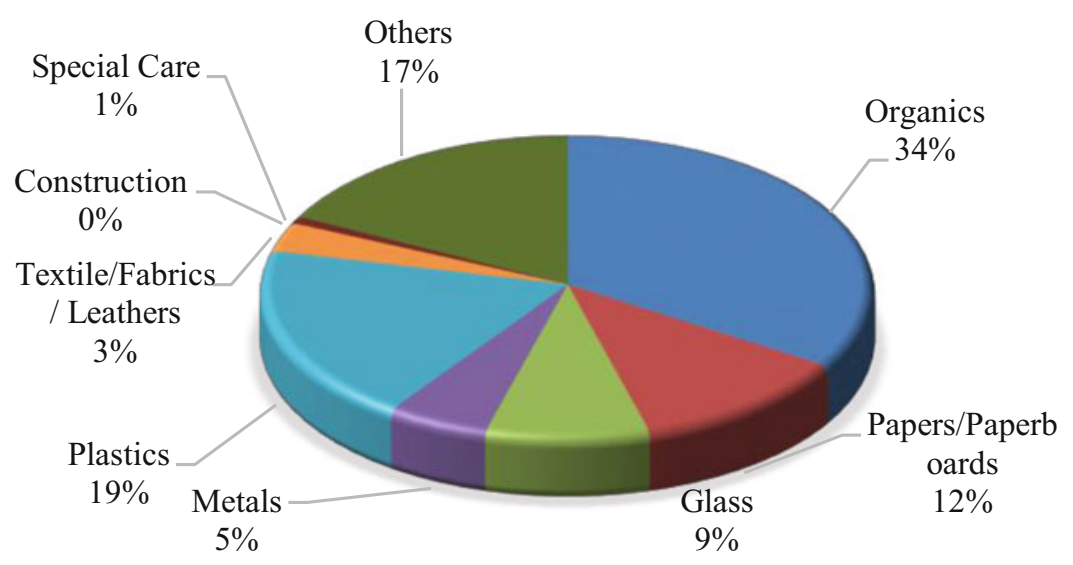

Fig. 3 Quantification of waste generated by the City of Johannesburg, South Africa

implementation of the SDGs and fourth industrial revolution. The high number of plastic calls for the introduction of the bioplastics to protect the flora and fauna. This adds up pressure on the added value recycling and reduction of waste to landfills. The climate change future policy in developing countries is likely to be both promoted by climate technology transfer and public-private cooperation (crosssector partnership) through the technology mechanism of the nexus and inclusion of the gender.

\section{Water Security and Pursuit of Energy, Food, and Earth System Resilience}

Water is inseparably linked to food and energy production. The interdependence of energy on water is seen in transport, extraction, power generation, irrigation of biofuel crops, processing of fossil fuels, fuel cells, energy storage, etc. (Birol 2012). The emerging issues are cultivated on the regions that are facing adoption of the appropriate water management policies, water scarcity, and approaches fostering the allocation and sustainable use of resources while promoting economic growth. Due to human activities and availability of the water resources, Africa is one of the most vulnerable regions. In order to maximize the efficiency of using the resources, nexus is offering an integrated approach that analyzes the synergies and trade-offs between different sectors whereas adapting optimum institutional and policy arrangements (Markantonis et al. 2019). Lifecycle approaches are widely used by the industry for the assessment of the risk water management. The absence of lifecycle database to complement developing countries' databases is a challenging issue that extensively improved the national accounting system. More positive economic opportunities are created in desalination technologies, smart metering, leak detection (prevent water loss), online water treatment, sensor technology in parameters detection, and smart use of ecosystems to collect and store water and 
carbon. Water security encourages the population to increase capacity of sustainable water access with adequate quality and quantities for human well-being, sustaining livelihoods and socioeconomic development. This ensures the protection against water-borne diseases, emerging contaminants, and water-related disasters by preserving a climate with peaceful ecosystems and political stability (Hassan et al. 2018; Matheri 2020; UN Water 2013).

The food challenges from water perspectives include raises irrigation demands, diminishing institutional that influences the irrigation schemes, groundwater pumped variables, production shifts poleward, higher elevation, water and wastewater treatment and reuse of the resources (Scott et al. 2018). The energy challenges from water perspectives include low water footprint solar PV and wind, dry cooled thermogeneration, water footprint of multiple energy portfolios, energy generation degrades water quality, energy generation from water resources (hydropower, fuel cells, anaerobic digestion), and energy storage (Scott et al. 2018). Construction of the decentralized solar-powered desalination systems in the dry areas will be one of the game changer deployments of the sustainable technology solution in disadvantaged communities in developing countries. This helps bring millions of liters and address perennial water shortage and thus reduction of water-borne diseases.

\section{Water Pricing}

Water pricing currently is often underestimated which is fundamentally of importance in the economic issues that affect the implementation of the nexus on water use. Water pricing is an economic instrument which efficiency depends on the designed and implementation of the WEF nexus framework and investment. This is with regard to the policy choice, economic pursuit, realities, environmental, social, opportunity cost, and cultural cost. Developing countries' adaptation of the EU members' states law and policies on water pricing is one of the key goals in sustainable development (Markantonis et al. 2019).

\section{Food Security and Pursuit of Water, Energy, and Earth System Resilience}

Food production needs energy, productive land, and water to grow crops, process food, and maintain livestock. Organic fraction of waste can also be put into value by converting and generating energy via anaerobic digestion and fermentation processes, while other technologies go more to gasification and direct combustion to generate energy and organic fertilizers (Matheri 2020). Such bidirectional links are complicated by the specific external factors that modify the chemical and physical characteristics and composition of water flows. Food consumption (changing dietary habits) and generation of the food waste have large effects on the nexus. This is yet to be accounted in SDGs and cannot be treated with isolation from one another and alternative in the attainable chosen pathways in the water and food systems. Food security exists when everyone, at all times, has economic and physical access to adequate nutritious, safe, and sufficient food that meets their specific dietary 
preference and needs for an healthy and active life (Hassan et al. 2018). The water challenges from food perspectives include land degradation (salinization), water use, wastewater use for food production, supplemental irrigation of rainfed land, high water footprint of agriculture, and ensuring water allocation to irrigation. The energy challenges from food perspectives include mitigate hydropower-farming trade-offs, energy intensification of agriculture, energy intensification of the biofuel production and food transport, and competition between energy production and food security. One of the futures of food in climate change is podcast on the plant-based meat change to counteract the intensive use of energy.

\section{Biophysical and Biogeochemical Land-Climate Systems}

The evidence of the land cover matters and climate systems is on early paleoclimate model studies and impacts on human-induced deforestation at margined regions. Changes from land conditions due to human activities affect the global climate change. This is driven by changes in emission removals of the GHGs (e.g., $\mathrm{CH}_{4}$, $\mathrm{CO}_{2}, \mathrm{~N}_{2} \mathrm{O}$ ) by biogeochemical effects. Any land redistribution and local changes on the water vapor and energy between the land and atmosphere influence the biophysical effects on regional climate. The terrestrial biosphere interacts with oceans through influx of nutrients, carbon cycle, water, and particles. This interaction affects crop yield, frequency heat waves, intensive heat waves, rainfall, and air quality. Land has net sources of $441 \%$ of the $\mathrm{CH}_{4}$ emission between 2006 and 2017. IPCC has established GHG inventories and earth system models (ESM) on deforestation and afforestation as to reduce the anthropogenic $\mathrm{CO}_{2}$ emission. This combines biophysical and biogeochemical processes to the land-climate system processes. IPCC reports that about one-quarter of 2030 mitigation pledges by countries in initial nationally determined contributions (NDCs) under Paris Agreement is expected to come from land-based mitigation (Jia et al. 2019). Some of the mitigation responses have a response option on technical potential for $>3 \mathrm{GtCO}_{2 \text {-eq }}$ year $^{-1}$ by 2050 through reduction of the carbon dioxide. These technical aspects include afforestation, waste to energy (bioenergy), wastewater recycle, and carbon capture and storage (carbon dioxide removal-CDR). The estimate includes sustainability and cost consideration with social-economic consideration on the climate changes or non-GHG climate forcing. Rising $\mathrm{CO}_{2}$ concentration limits stomatal opening of the moisture content in the soil, thus reducing transpiration (land-based water cycle/ hydrological on climate change). This increases the aerosol levels, declines surface winds, and increases solar radiation to the ground. The impact of the climate-related extremes on land includes the disruption of the water-energy-food production and supply chain, alteration of the ecosystems, hydrological cycle, surface temperature, atmosphere composition, morbidity and mortality, and damages of the infrastructure and settlements and human health. Advanced knowledge and optimization of the mitigation and adaptation with coordination of the sustainable land use and management across all sectors are required to achieve better livelihood, food security, energy security, and water security and improve human health, biodiversity, quality 
of the local environment, and equitable sustainable development. This is through the modification of the regional and global climate change, seasonal and annual climate variation, extreme weather, and human activities on the land, e.g., deforestation, afforestation, and forest management. Incorporating land-climate processes into climate projection allows emotional intelligence and artificial intelligence to take shape through understanding land's response to climate action and better quantify the potential of land-based response options for the mitigation of climate change (Jia et al. 2019).

\section{Nexus Contributions to Job Market}

When developing or implementing a nexus, approaches with regard to minimization of high transaction costs should be an added value in economic measurement. Furthermore, energy and water generation and distribution have high characteristics of being monopolized in the developing countries. This creates merits and demerits to the end users. In general, the CLEWS' nexus has great potential to create new job opportunities and improving living standards in the developing countries. There is a higher need to accelerate the process of the WEF management of emergence of new employment opportunities. Investment of the research and development and implementations on nexus approaches could induce a positive economic effect through job creation. Other disrupted sectors should further be redeveloped, attracting additional meaningful investments and producing new employments within a nexus framework of policies and governance, auditing, and monitoring. Governments have the biggest role to play in the nexus implementation either by making relevant policies or providing funding that subsidizes new technologies and contributes to the welfare of society and enrichment of the emerging market gap.

\section{Carbon Tax}

Developing countries' economic transformation and creation of employment through green economy and digitalization will be one of the COP26 green deal agendas. This is with the transition of the national development goals (NDG) 2030 and transition of the low-carbon economy and sustainable development goals as per the economic partnership agreement between the European Union (EU) and developing countries. The commitment through policy-making is paramount in the carbon taxation. The carbon tax is levied on carbon content of fuels (energy and transport sector) and carbon emission trading in the form of carbon pricing $\left(\mathrm{CO}_{2}\right.$ equivalent tax/pollution tax). The tax offers potentially cost-effective means of the reduction of the greenhouse gas emissions by shifting the cost from society to companies that create the emissions (the more the emission, the more the cost). South Africa has spearheaded the developing countries in the carbon tax 2019 (carbon tax act No.15 of 2019) meant to curb the carbon emissions (green house emission, industrial processes, fuel combustion, and fugitive emissions) as mitigation to climate change, 
which is cost-effective and economically efficient. The cost of the impact of climate change to food pricing, water, infrastructure, health, conflict, and disasters tends to shift to polluters (global economy shifts toward lower carbon economy). The impact of crop disease and rainfall changes, extreme storms and drought, and temperature changes has shift changes in food prices and food security. This has direct impact on the carbon taxation (Republic of South Africa ZA 2019).

\section{Data-Driven Nexus}

It is a big challenge to relatively obtain national data for the nexus. Small numbers of bodies (e.g., IRENA. World Bank, IEA, UN) share production, transformation, and consumption data. This remains a key challenge in the mitigation of climate change. Examples os data include water evaporations rates from hydro-powers, flood controls or irrigation, water requirement in energy production and food production, mixed SI units on the data presentations, pattern use of water with regard to locations. Data gap is even larger if fully life cycle of the technology is considered (Ferroukhi et al. 2015).

Matters concerning the big data in nexus' availability and accessibility should be of high priority in policy-making. Nexus is based on a holistic environmental and economic perspective, which should use reliable, consistent, and comprehensive data. It is also imperative that data source across the nexus sectors is comparable in terms of resolution and accuracy. Efficiency in implementation of the nexus is dependent on high-accuracy economic databases that support sustainability. Research and development, scientific institutions, and stakeholders can initiate the collection of open data, in order to build a sustainable database for analyzing the nexus. This can add value and be generated only through workable partnerships between the private-public sector, NGOs, knowledge institutes, and local and regional stakeholders (Markantonis et al. 2019).

\section{Industry 4.0 in Nexus and Climate Resilient}

The nexus pillars of sustainable development need to be explored in the numerical modelling (i.e., economic modelling; kinetic modelling; life cycle assessment (LCA); WEF modelling; multi-criteria decision analysis (MCDA); CLEWS' modelling; resource flow; network analysis; remote sensing, geospatial, and hydrologic models; finance models; climate models; material and energy models; land-use models; institutional analysis; environmental management; indicator models; social science and integration models; system analysis) (Albrecht et al. 2018). The climate change estimation is based on the sparse station coverage, particularly on scrutiny of GDP data. Lack of transparency in data sources and collection methods, lack of details on methods of aggression, and lack of metadata have led to differences between GDP estimates, adjustment to historical data, nonrandom errors, and inhomogeneity in time series. Good quality data is paramount to reliable physical and 


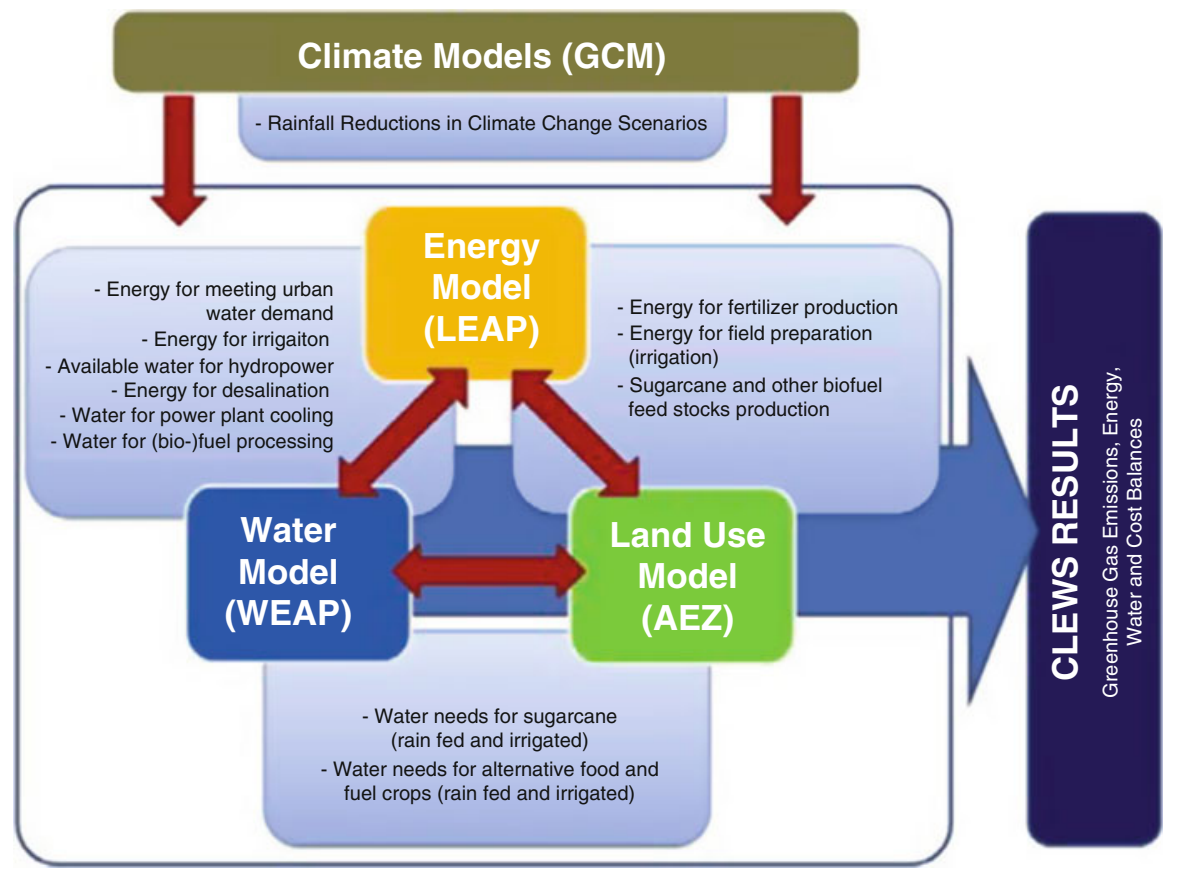

Fig. 4 The CLEWS' framework founded upon the LEAP, WEAP, AEZ, and GCM models

economic modelling of the nexus and climate sector (Conway et al. 2015). Climate, land, energy, and water systems (CLEWS) are integrated. The CLEWS' resource assessment and interlinkages with new paradigms are presented in Fig. 4 (Howells et al. 2013; Welsch et al. 2014).

The CLEWS serve as highlights and dynamics that overlook the system approach to sustainable development. The CLEWS' framework is developed by integrating the LEAP (energy), WEAP (water), GCM (general circulation model, climate), and AEZ (agroecological zoning, land) to produce the GHG emissions, water, and energy balance. The model outcome exercises policy development and resource assessment approach through linking existing single-resource modelling tools (Howells et al. 2013; World Bank Group (WBG) 2016).

\section{Modelling of the Water-Energy-Food-Land-Climate Nexus}

The climate-water-energy-food-land are indirectly and directly interlinking. Nexus unique assessment and monitoring is based on indicators and interlinkages to better understand the potential synergies and trade-offs. Quantification and characterization are mostly needed in decision-making. Nexus modelling and framework are classified as (Hassan et al. 2018; Bizikova et al. 2013): 


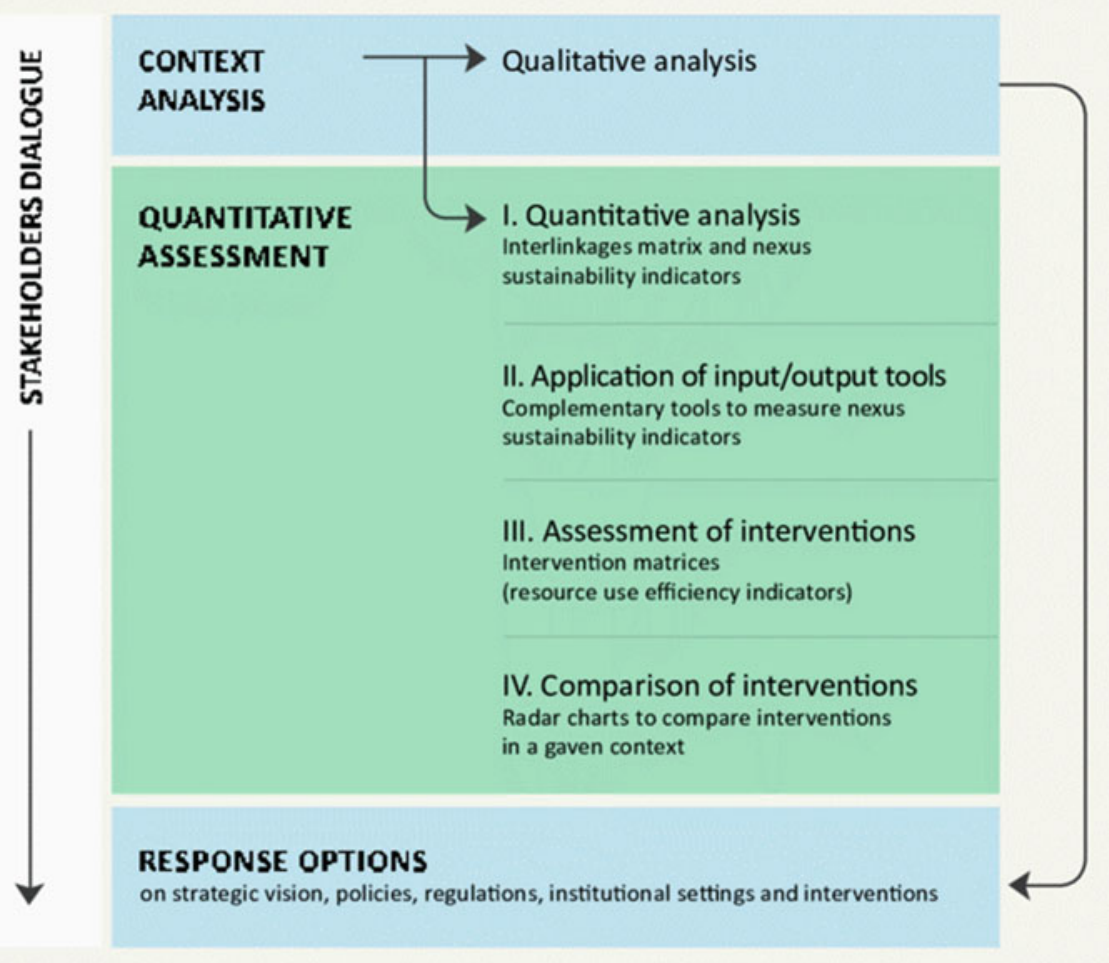

Fig. 5 FAO component of the nexus assessment

- Type of models: quantitative analysis models, simulation models, and integrated models

- Geographical scale in addressing intercountry levels

Figure 5 indicates the components of the nexus assessment (Hassan et al. 2018). For example, assuming change in water $(\Delta \mathrm{W})$, reduces freshwater availability and create shift in energy $(\Delta \mathrm{E})$ with limiting cooling power that leads to load shedding (power rationing) and water scrubber thus increase shift of climate change $(\Delta \mathrm{C})$ and land use. The interlinkages are unique and can go to any directions. The 20 interlinkages are summarized below:

- Water: WL, WF, WE, WC

- Energy: WL, EF, EC, EW

- Land: LF. LW, LC, LE

- Food: FE, FE, FL, FC

- Climate: CF, CW, CE, CL 
The analysis of the interlinkages can be analyzed well by the use of artificial intelligence tools (e.g., artificial neural network, ANN), statistical tools (e.g., multicriteria decision analysis (MCDA)), and conventional modelling concepts. The nexus pathways can be restructured in the first to fourth order. Similar nexus can be constructed with fourth-order interlinkages for the whole nexus making it 120 (Laspidou et al. 2018). The multicentric approach will add complexity with interconnection, trade-offs, and drives on nexus assessments (Simpson and Jewitt 2019).

\section{Adaptation of Climate Change Technology Transfer in Developing Countries}

Currently, combating anthropogenic climate change in developing countries is carried out through the transfer of environmentally sound technologies (EST). This is a widely recognized priority for global environmental policy. Climate change technology transfer and policy analytics are of high success factors underlying collaboration between private and public sectors in developing countries. Climate change future policies in developing countries are likely to both be promoted by climate technology transfer and public-private cooperation (crosssector partnership) through the technology mechanism of the water-energy-food nexus and inclusion of the gender. Building partnership mechanisms can reduce cost and increase local clean development mechanisms (CDM). The difficulties in achieving the CDM include first a sidelined investment by investors on diversifying a project away from cheap forms of climate change mitigation by increasing cost and broader development outcomes. Second, the technology dividends are uncertain and often reflect on preference of host government or deliberative processes involving the stakeholders. Third, green climate fund shortage or project investment guidelines combine production cost, human capacity, and innovator multidisciplinary. Overcoming the barrier allows the smart climate-resilient and efficient integrated energy-water-food nexus system in a developing country: Industry 4.0 with climate change friendly investment to proceed quicker and implement the development dividend (Forsyth 2007). The costs of climate technology transfer and increase local representation in establishing the development dividend can be reduced by cross-sector partnerships (CSPs). CSPs can comprise of orthodox public-private partnerships, where governments make contracts with a privatesector company in order to provide Intelligent Network Infrastructure or services more efficient than the state (Forsyth 2005, 2007). Climate change policy and technology transfer minimize the transaction costs, strengthen the collaboration, build capacity, increase public trust and accountability, and enhance environmental governance under the climate change convention and application of the CDM (Forsyth 2005; COP25 2019b). 


\section{Nexus and Research Gap}

The concept of the nexus has been received in the business, academics, and policy sectors with a few implemented projects on the ground. The major discussion is how to implement and shift from the ideal concept of the theory based on practice and policies. The nexus methodology emphasis on water-food is majorly researched on hydrological, ecological, and agronomic integrated models and analysis with limited focus on the governance issues of the resources. Versatile methodology to quantify the interlinkages between the WEF and climate change is required. Improving the formulating existing methodology and practices is of high priority to advancing the adoption of the nexus approach. Lack of the reliable data (big data/open source) in the digitalization, electrification, decentralization, and decarbonation world (fourth industrial revolution, Industry 4.0) is a major barrier toward implementation of the WEF nexus approach. Lack of the reliable comprehensive analytic tools is another highlighted concern. Development of critical soft skills (sciences/social/business, STEM) in integrated software and online platform is helpful in addressing the potential synergies and trade-offs in the nexus. Convectional models and AI-based models' development is of a big challenge, and a big question is how nexus and climate change interact and are quantified. In providing important strategies for the SDGs, the integrated models and managements for developing countries is enhanced.

Climate change on the WEF is another critical aspect of high importance on resource availability, distribution, and interconnection to the WEF. How does climate change affect the nexus? What are the impacts of climate change to the nexus? Which agent of change needs to be implemented in WEF NEXUS? Is there political good will in the addressing climate change? What are the governance and policy coordination in place? These fundamental aspects can be addressed based on smart climate-resilient and efficient climate change adaptation, international commitment, corporation and stewardship, new and refurbished green infrastructure projects, green funding, reward and awarding the environmental champions, and payment for ecosystem services (Hassan et al. 2018). The methodological challenge, supports, and opportunities that are associated with robust quantification of the WEF nexus are indicated in Fig. 6 (Chang et al. 2016):

\section{Analytics Framework}

The nexus provides a set of guidelines that aims in creating a great and equal level playing field for all sectors while achieving the aims of the SDGs that are multilevel approach and cross-sectoral to climate change. This comprises of six categories (Hoff et al. 2019):

- Nexus framing creates specific understanding on key issues from that which explores the interlinkages between the different sectors and resources. 


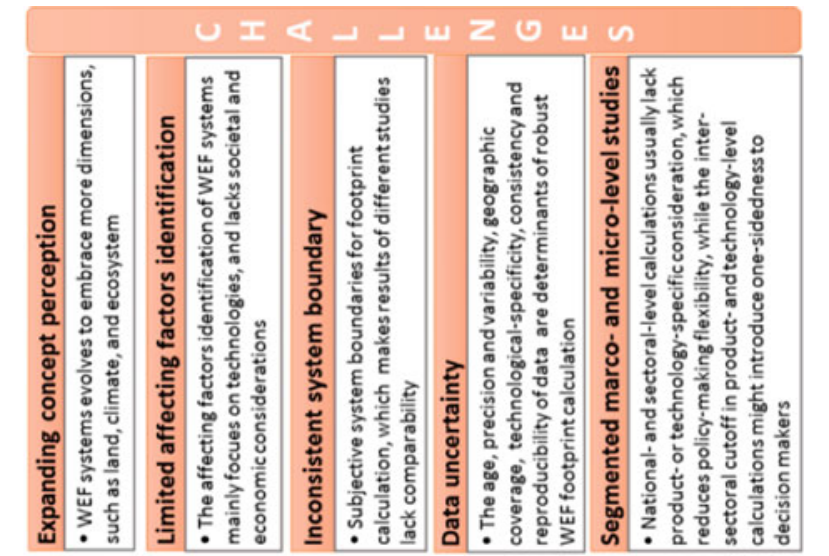

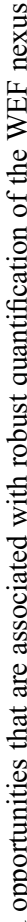
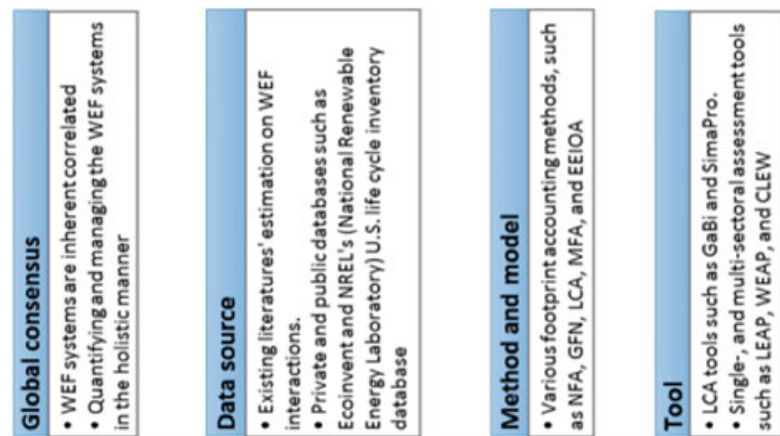

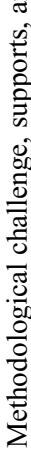

\section{n $\curvearrowright \propto \circ \propto \vdash n$}


- Nexus opportunities create a category on how to identify a new approach and adding values in context by improving cross resources productivity, reducing resources and environmental degradation, reducing human insecurities/unemployment/poverty, and increasing climate resilience.

- Technical and economic nexus (nexus savings) assesses possible potential benefits from implementation of nexus approaches through multifunctioning production systems, cross resources, and cross-sector recycling.

- Stakeholders' involvement specifies different types and levels of stakeholders involved in the nexus, e.g., private-public sectors and civil society in overseeing the implementations.

- Conditions' framework addresses factors such as policies, technical solution, scalability, initialization, bridging mechanisms, integration of SDGs and NDGs, and innovations (start-ups, incubation, and entrepreneurship).

- Monitoring and evaluation (M\&E) serves as an indicator for the required data for implementation of the nexus. This is because it is dynamic objectives, composition of stakeholders, and processes.

The overall methodology of the WEF nexus management approach is performed in three steps (see Fig. 7): (1) overview characterization (identifying and quantifying the connectivity between nexuses), (2) integrated models and analysis (climate-landenergy-water) of the nexus system, and (3) performing future management scenarios to help policy and decision-making (Tashtoush et al. 2012).

The nexus framework is seconded by the holistic resources planning showed in Fig. 8 (Kulat et al. 2019).

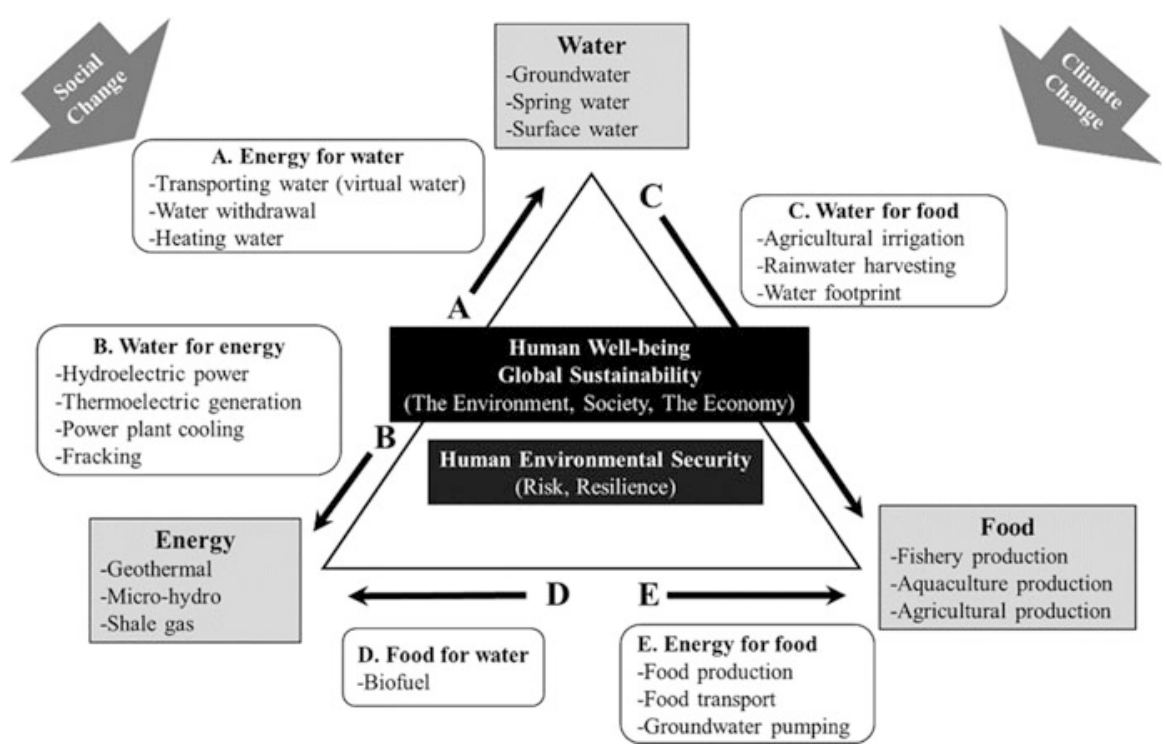

Fig. 7 Water-energy-food nexus analytics framework 


\section{Nexus Securities and Environmental Protection}

Climate change intensifies high competition and trade-offs between the WEF resources. The potential impact of the climate change is manifested by rise in temperature, more energy demand, and more water demand. Urbanization and population increase (industrialization) account for the $75 \%$ of the energy consumption and emission of the $75 \%$ of the greenhouse gases (GHGs). This creates high opportunities for the decentralization, decarbonization, and digitalization systems that improve the resource efficiency and implementation of the nexus approached. Suitable adaptation of the climate change demands efficient use of water, energy, and food resources to fight against vulnerability. Figure 9 illustrates the conceptual

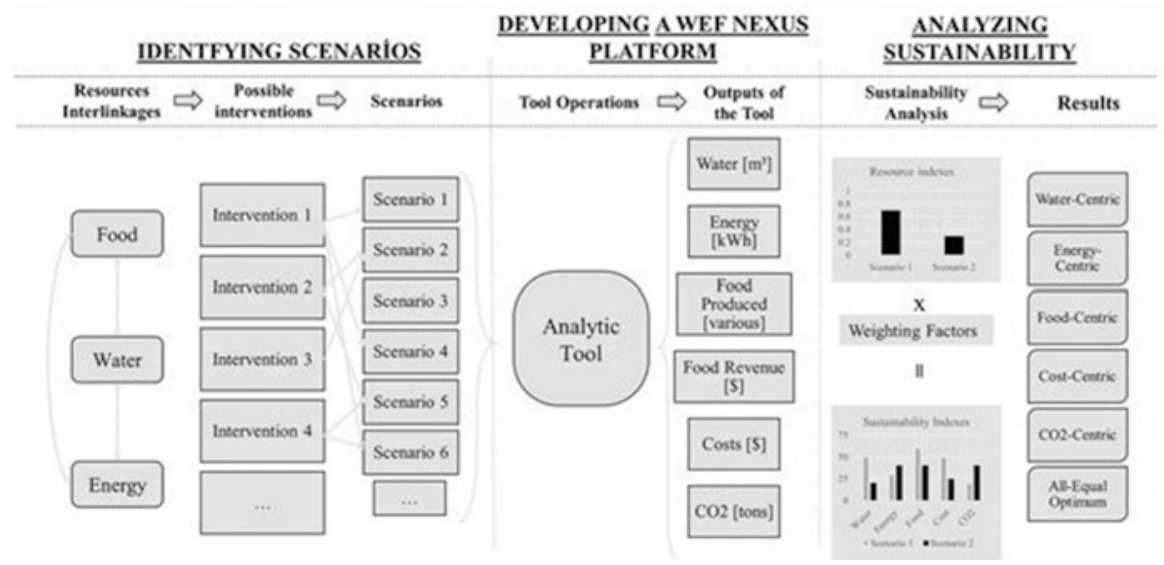

Fig. 8 Holistic water-energy-food nexus resources planning

Fig. 9 Conceptual framework of the water-foodenergy nexus and climate change integration

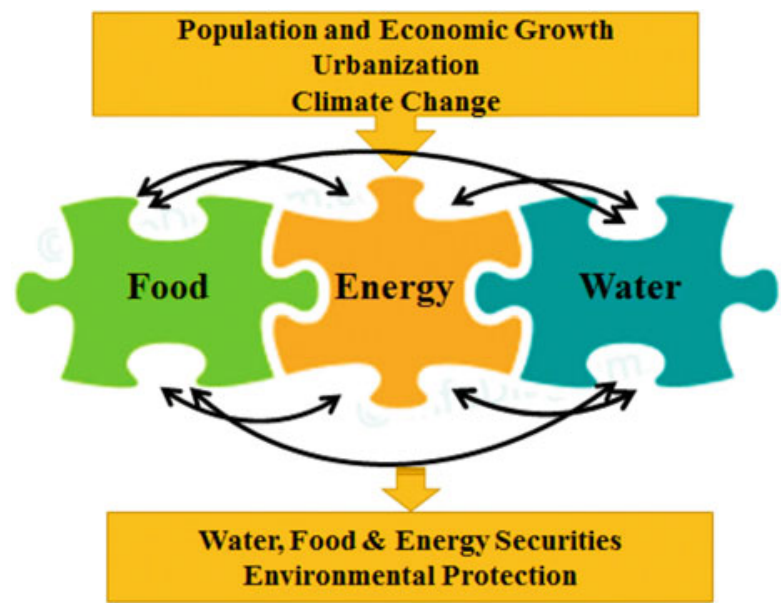


diagram of the WEF nexus with link between the WEF and climate change integration (Tashtoush et al. 2012).

The global emission of carbon dioxide has increased with almost 50\% since 1990 . The SDGs and NDGs cannot be achieved without addressing the climate emergence (SDGs, UN 2019). The region that is vulnerable to climate change encourages to adapt measures that are implementable and have surety of the WEF security. Enhancing efficiency of small-scale water supply systems and consolidated small services helps reduce vulnerability to climate change of the systems (policy initiative to adapt the climate change in water sector); collaboration in data collection and analysis to mitigation of climate change are key to sustainability of the WEF nexus. Adaptation of the climate change can be improved by building ecological networks that connect ecological to local governments, thus improving decision-making. Spatial equilibrium models seek to optimize resource allocation in various scales, thus providing realistic estimates of the value and into accounting alternative use of the disrupting technology. WEF nexus needs to be integrated to a smart climate resilient with inclusion of the governance and stakeholders. This serves as a comprehensive tool in decision-making toward sustainable resources in climate change (Volk 2014; Daher and Mohtar 2015). Recognition of spatial and sector interdependencies should inform policies, investment, and institutions for enhancing WEF security and climate change (Conway et al. 2015).

\section{Policy and Governance (Coordination and Collaboration) for Climate Change}

Climate gas (GHG) emissions and climate risks in countries are not only city government's concerns but also rural government oversight concerns (climate governance). The drivers, consequences, and dynamics of climate change cut across jurisdictional boundaries that require collaboration and coordination of governance across nongovernment and government sectors. Climate change governance is within broader political and social-economic context negotiable with Conference of the Parties (COP) to the UNFCCC (Romero-Lankao et al. 2018). Strategies, policies, and plans provide guidelines and framework for practical coordination and collaboration on CLEWS. Overarching climate change policies integrate the practical collaboration and giving timeline to the policies and their inclusion of climate changes and nexus. Persistence of these strategies recognized a gap in governance (policies and planning). The emphases on a formal model of contract may disincentivize regular collaboration and not only the barrier to cross-sector collaboration and coordination but budge and financial agreements. The issues of the regional security (power imbalance) are a sector interest overriding the climate change agenda. The integrations of the national-level strategies, planning, policies, and age and gender inclusion encourage action on climate change (Pardoe et al. 2018). Increase policy synergies among transformative investments that require a holistic approach with process innovation that fueled a higher level of nonhuman and human capital. Formation of the transboundary with globalized decision-makers 


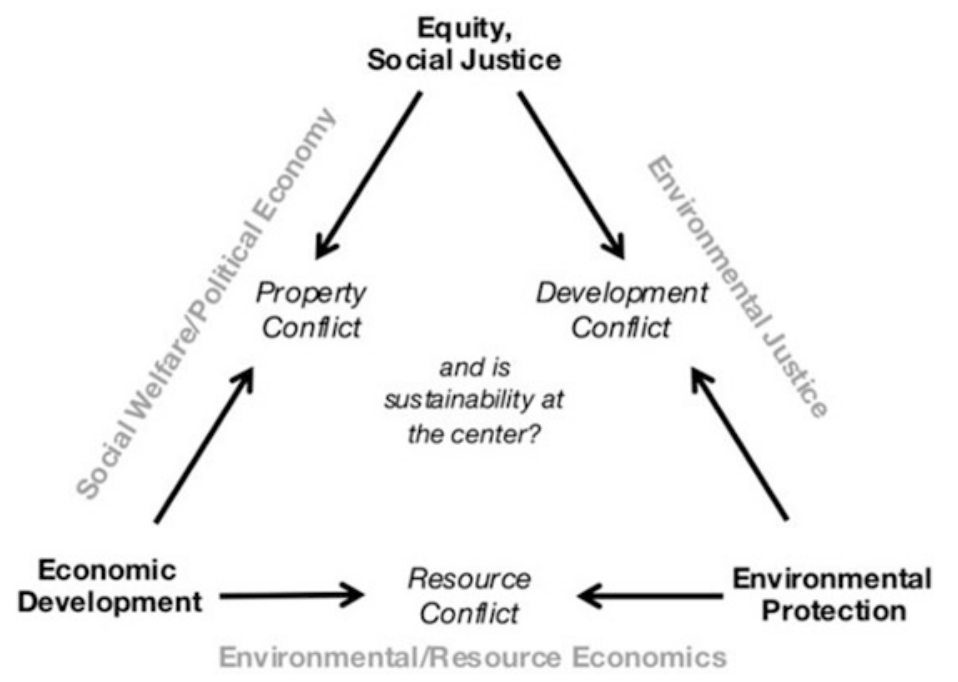

Fig. 10 Three fundamentals of planning

creates integration and enhances benefits through the climate-land and WEF nexus and equitable distribution. Creation and promotion of the gender equality environment enhances the nexus investments and implementations with enhanced family wealth that widens skills and knowledge (Mishra et al. 2019; RES4 Africa Foundation 2018). Collaborative, informed decision-making and equitable needs in transformation response of the climate change as well as fundamentals of the legal framework, leadership, land-use regime, land ownership, energy use, food production and distribution, public participation, information sharing, financial resources, growth, and ethos shape the climate change governance (Romero-Lankao et al. 2018). The three fundamentals of planning are presented in Fig. 9. It consists of the development conflict, resources, and property with three broad political/social institutions to manage environmental justice, regulation, environmental economics, and social welfare (Campbell 2013; Fig. 10).

Despite deficiency, state, government, provinces, municipalities, counties, and nongovernmental and governmental action on addressing climate change the jurisdiction over many dimensions of adaptation and mitigations reside on financial and technical capability and policies that hold greatest potential to create legitimate and effective response strategies (Romero-Lankao et al. 2018).

\section{Equity, Climate Change, and Environmental Justice}

Major cities are characterized by socioeconomics of different diversifications that are often accompanied with the stratification on gender, race, professional classes, cultures, age, ethnicity, and ability. This gives rise to endure climate stresses and 


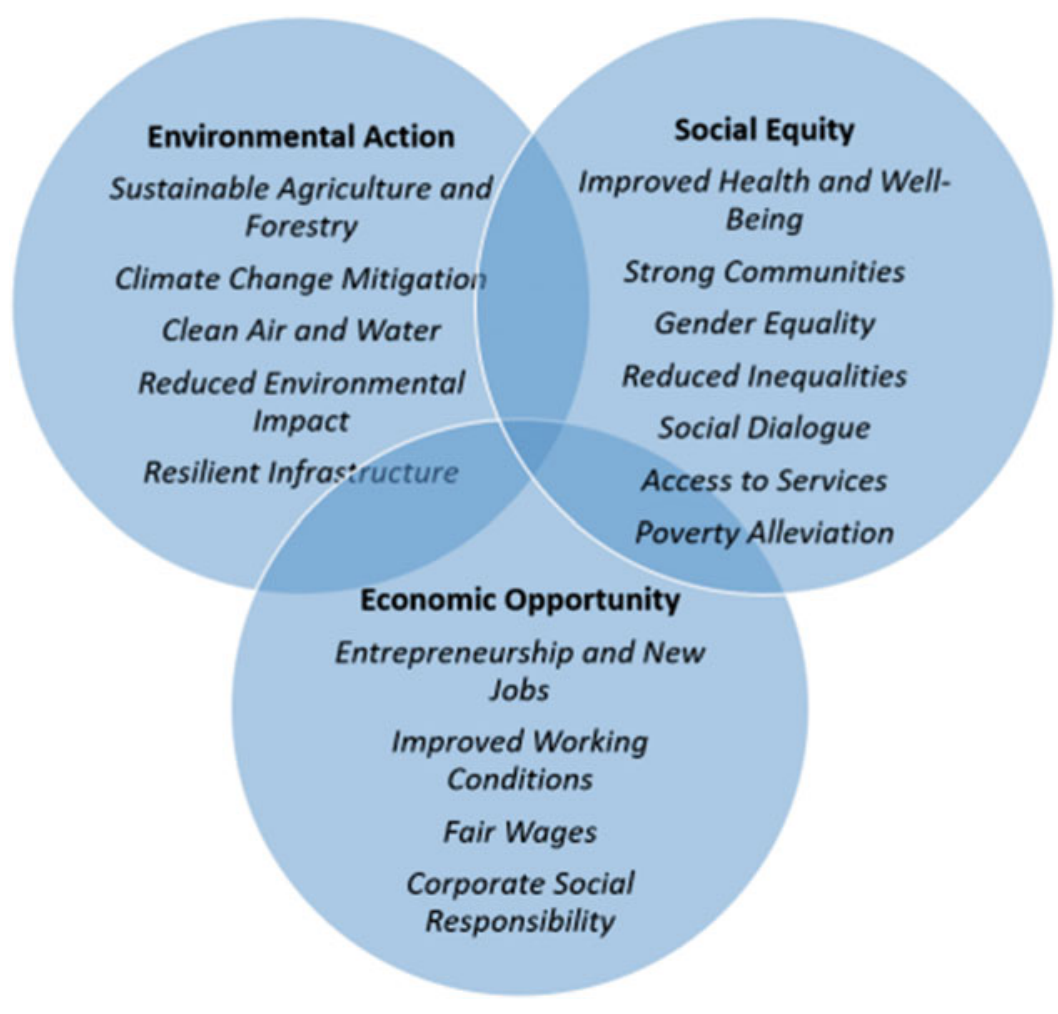

Fig. 11 Interconnected benefits and dimensions of inclusive climate action (Reckien et al. 2018)

minimize climate risks. Lower social class, disadvantages in the community, hazard prone areas, ethnics, and racial minorities increase their susceptibility to the impact of climate change and reduce their capacity to adapt (Rosenzweig et al. 2015).

Climate change vulnerability is driven by (1) resource influence by social characteristics, (2) ineffective planning and absence of community engagement due to governance and institutional weaknesses, (3) failure of the urban developers in providing accessibility to critical infrastructures and services, and (4) occupational health that leads to physical exposure at different levels. As the climate event such as drought in prone areas becomes more frequent and intense, this can increase the scale and depth of poverty overall. Gender inequality is pervasive and cuts across to disability, income, and literacy that in turn contribute to differential consequences of climate change. Mobilization of the resources increases environmental justice, and equity of climate change requires participation of the locals, international bodies in involvement of the nontraditional resources, finance civil society, public-private sector, monitoring and evaluation, and principles of transparency (Reckien et al. 2018). Figure 11 indicates the interconnected benefits and dimensions of inclusive climate action. 
The primary goal in achieving environmental justice and equity in climate change is for the urban climate policies to foster human beings, economic and sustainable social development, social capital, access to land, security tenure, risk reduction infrastructure, access to CLEWS; integrate community and stakeholders, in decision-making; adjust climate change policies by ensuring resilience and equity goals; and develop a periodic monitoring and evaluation using fair indicators and progress measurement, resilience objective and feasibility, equitable resources, budgetary transparency, resource allocation scheme, and equitable resilience outcomes (Rosenzweig et al. 2015; Reckien et al. 2018).

\section{Conclusion and Recommendations}

The CLEWS nexus is a concept of integration that accesses the resources such as water, food, and energy that are inextricably dependent and linked to one another and have a strong interaction with the environment and climate change. The interlinkages exist between nexuses that manifest in providing exploring opportunities that explore the disruption, policies, and alternatives for increasing the use of resources and sustainable resources management and minimizing the environmental impacts. The nexus and climate resilience offer great opportunities that integrate and manage the disruptive technology in a more sustainable manner by promoting local and regional cooperation and peace; harmonizing the policies, legislation, and strategies; creating proper resource coordination; improving resilience; and reducing vulnerability to attainment of the region integration in-line with SDGs. The impact of the climate-related extreme on land includes the disruption of the water-energyfood production and supply chain, alteration of the ecosystems, morbidity and mortality, and damages of the infrastructure, settlements, and human health. Advanced knowledge and optimization of the mitigation and adaptation with coordination of the sustainable land use and management across all sectors are required to achieve better livelihood, food security, energy security, and water security improve human health, biodiversity, quality of the local environment, and equitable sustainable development. Climate action future policy in developing countries is likely to be promoted by climate technology transfer and public-private cooperation (cross-sector partnership) through the technology mechanism of the water-energyfood nexus and inclusion of the gender. Building partnership mechanisms can reduce cost and increase local clean development mechanisms (CDM). Agenda 2030 sustainable development, Paris agreement, and national development policies are alignments to advance climate-resilient development and green deal that enhance stainable future.

Recommendations arising include:

1. Great investments into nexus with strong collaboration of the multidisciplinary.

2. Governments should work together to achieve green circular economy with smart and intelligent novel solutions.

3. SDGs 17 need to be widely explored and policies clarified. 
4. Development of new tools to investigate the interconnection of the WEF nexus with land and climate change.

5. Research and development should be enhanced before decision-makings on sustainability and efficiency.

6. Better understanding is required of the trade-offs between nexus and ecosystems.

7. It is important to take action of the spatial reach of intersectoral interdependencies (pricing, control instruments, and command) and effects in the multilevel governance systems to ensure appropriate participation by affected sectors and stakeholders.

8. Data shortages should be reduced by encouraging open-source digitalized systems with capacity building support on sustainable monitoring and data management systems.

9. Introduction and enhancement of the existing free trade movement on the borders will enhance reaching the SGDs more than expected.

10. Use of the artificial intelligence solutions (nexus and climate change digitalization) on WEF and land and climate change applicability in decision support management, i.e., machine/deep learning, blockchain, remote sensing, IoT, big data, etc.

11. Introduction of the climate change coding (code for climate change and nexus) will enhance early data analytics and action (action toward digitalization, digital earth).

12. Enhanced, efficiency and accessibility of the green climate funding will enable preparation, implementation, and strategic workstreams of national determined contributors and adaptation-related elements of the Paris Agreement. The mechanism will minimize and address loss and damages associated with climate change impacts of developing countries' parties.

Acknowledgments The authors wish to acknowledge the South Africa Water Research Commission (WRC), Project No. K5/2563 for funding; University of Johannesburg (UJ); Enel Foundation; European Union Institute; Process, Energy, Environmental Technology Station (PEETS) funded by Technology Innovation Agency (TIA) through the Department of Science and Technology (DST); SANEDI; City of Johannesburg (CoJ); Gladtech International, Kenya; South Africa's wastewater treatment plants; Innovation Hub; and water utilities, managements, and staffs for capacity building and knowledge transfer.

\section{References}

Albrecht TR, Crootof A, Scott CA (2018) The water-energy-food Nexus: a systematic review of methods for nexus assessment. Environ Res Lett 13(4):043002

Birol F (2012) World energy outlook 2012. International Energy Agency, Paris, p 633

Bizikova L, Roy D, Swanson D, Venema HD, McCandless M (2013) The water-energy-food security nexus: towards a practical planning and decision-support framework for landscape investment and risk management. International Institute for Sustainable Development, Winnipeg

C40 (2020) https://www.c40.org/cities. Accessed June 2020 
Campbell SD (2013) Sustainable development and social justice: conflicting urgencies and the search for common ground in urban and regional planning. Mich J Sustain 1

Carter S, Gulati M (2014) Climate change, the food energy water Nexus and food security in South Africa. Understanding the Food Energy Water Nexus, WWF-SA

Chang Y, Li G, Yao Y, Zhang L, Yu C (2016) Quantifying the water-energy-food nexus: current status and trends. Energies 9(2):65

Chirisa I, Bandauko E (2015) African cities and the water-food-climate-energy nexus: an agenda for sustainability and resilience at a local level. In: Urban forum 26(4):391-404. Springer, Netherlands

Conway D, Van Garderen EA, Deryng D, Dorling S, Krueger T, Landman W, Lankford B, Lebek K, Osborn T, Ringler C (2015) Climate and southern Africa's water-energy-food nexus. Nat Clim Chang 5(9):837-846

COP25 (2019a) Enhanced Lima work programme on gender and its gender action plan. https:// unfccc.int/resource/cop25/cop25_auv_13gender.pdf. Accessed June 2020

COP25 (2019b) Enhancing climate technology development and transfer through the technology mechanism. https://unfccc.int/resource/cop25/cop25_auv_9_TEC_CTCN.pdf. Accessed June 2020

Daher BT, Mohtar RH (2015) Water-energy-food (WEF) Nexus tool 2.0: guiding integrative resource planning and decision-making. Water Int 40(5-6):748-771

Ferroukhi R, Nagpal D, Lopez-Peña A, Hodges T, Mohtar RH, Daher BT, Mohtar S, Keulertz M (2015) Renewable energy in the water, energy \& food nexus. IRENA, Abu Dhabi

Forsyth T (2005) Enhancing climate technology transfer through greater public-private cooperation: lessons from Thailand and the Philippines. In: Natural resources forum. Wiley Online Library

Forsyth T (2007) Promoting the "development dividend" of climate technology transfer: can crosssector partnerships help? World Dev 35(10):1684-1698

Hassan TA, Muhammad K, Ian M, Lars R, Justyna S (2018) The water-energy-food security Nexus; a review on Nexus literature and ongoing Nexus initiatives and policy-makers. Nexus Regional Dialogue Programme (NRD)

Hoff H, Alrahaife SF, El Hajj R, Lohr K, Mengoub FE, Farajalla N, Fritzsche K, Jobbins G, Özerol G, Schultz R (2019) A Nexus approach for the MENA region - from concept to knowledge to action. Front Environ Sci 7:48

Howells M, Hermann S, Welsch M, Bazilian M, Segerström R, Alfstad T, Gielen D, Rogner H, Fischer G, Van Velthuizen H (2013) Integrated analysis of climate change, land-use, energy and water strategies. Nat Clim Chang 3(7):621-626

Jia G, Shevliakova E, Artaxo P, De Noblet-Ducoudré N, Houghton R, House R, Kitajima K, Lennard C, Popp A, Sirin A, Sukumar R, Verchot L (2019) Land-climate interactions. In: Climate change and land. IPCC special report on climate change, desertification, land degradation, sustainable land management, food security, and greenhouse gas fluxes in terrestrial ecosystems

Kulat MI, Mohtar RH, Olivera F (2019) Holistic water-energy-food Nexus for guiding water resources planning: Matagorda County, Texas case. Front Environ Sci 7:3

Laspidou CS, Kofinas DT, Mellios NK, Witmer M (2018) Modelling the water-energy-food-land use-climate Nexus: the Nexus tree approach. In: Multidisciplinary digital publishing institute proceedings

Markantonis V, Arnaud R, Karabulut A, El Hajj R, Altinbilek D, Awad I, Brugemann A, Vangelis C, Mysiak J, Lamaddalena N (2019) Can the implementation of the water-energy-food Nexus support economic growth in the Mediterranean region? The current status and the way forward. Front Environ Sci 7:84

Matheri AN (2016) Mathematical modelling for biogas production. University of Johannesburg, Johannesburg

Matheri AN (2020) Mathematical modelling of biological wastewater treatment and bioenergy production processes. PhD Thesis, Chemical Engineering, University of Johannesburg 
Matheri AN, Ntuli F, Ngila JC, Seodigeng T, Zvinowanda C, Njenga CK (2018a) Quantitative characterization of carbonaceous and lignocellulosic biomass for anaerobic digestion. Renew Sust Energ Rev 92:9-16

Matheri AN, Mbohwa C, Ntuli F, Belaid M, Seodigeng T, Ngila JC, Njenga CK (2018b) Waste to energy bio-digester selection and design model for the organic fraction of municipal solid waste. Renew Sust Energ Rev 82:1113-1121

Matheri AN, Eloko NS, Ntuli F, Ngila JC (2020) Influence of pyrolyzed sludge use as an adsorbent in removal of selected trace metals from wastewater treatment. Case Stud Chem Environ Eng

Mishra A, Appadurai AN, Choudhury D, Regmi BR, Kelkar U, Alam M, Chaudhary P, Mu SS, Ahmed AU, Lotia H (2019) Adaptation to climate change in the Hindu Kush Himalaya: stronger action urgently needed. In: The Hindu Kush Himalaya assessment. Springer, Cham, pp 457-490

Newell JP, Goldstein B, Foster A (2019) A 40-year review of food-energy-water nexus literature and its application to the urban scale. Environ Res Lett 14(7):073003

Nhamo L, Ndlela B, Nhemachena C, Mabhaudhi T, Mpandeli S, Matchaya G (2018) The waterenergy-food nexus: climate risks and opportunities in southern Africa. Water 10(5):567

Pardoe J, Conway D, Namaganda E, Vincent K, Dougill AJ, Kashaigili JJ (2018) Climate change and the water-energy-food nexus: insights from policy and practice in Tanzania. Clim Pol 18 (7):863-877

Reckien D, Lwasa S, Satterthwaite D, McEvoy D, Creutzig F, Montgomery M, Schensul D, Balk D, Khan I (2018) Equity, environmental justice, and urban climate change: climate change and cities: second assessment report of the urban climate change research network. Cambridge University Press, New York, pp 173-224

Republic of South Africa ZA (2019) Carbon tax act 15 of 2019. https://www.gov.za/sites/default/ files/gcis_document/201905/4248323-5act15of2019carbontaxact.pdf. Accessed June 2020

RES4 Africa Foundation (2018) Applying the water-energy-food nexus approach to catalyse transformational change in Africa. RES4Africa Foundation

Romero-Lankao P, Burch S, Hughes S, Auty K, Aylett A, Krellenberg K, Nakano R, Simon D, Ziervogel G (2018) Governance and policy; climate change and cities: second assessment report of the urban climate change research network. Cambridge University Press, New York, pp 585606

Rosenzweig C, Solecki W, Romero-Lankao P, Mehrotra S, Dhakal S, Ali Ibrahim S (2015) The urban climate change research network (UCCRN) second assessment report on climate change and cities (ARC3-2), and the UCCRN hubs. Cambridge University Press, New York

Scott CA, Kurian M, Wescoat JL (2015) The water-energy-food nexus: enhancing adaptive capacity to complex global challenges. In: Governing the nexus. Springer, pp 15-38

Scott CA, Albrecht TR, De Grenade R, Zuniga-Teran A, Varady RG, Thapa B (2018) Water security and the pursuit of food, energy, and earth systems resilience. Water Int 43(8):1055-1074

SDGs, UN (2019) Goal 13: take urgent action to combat climate change and its impacts. https:// www.un.org/sustainabledevelopment/climate-change/. Accessed June 2020

Seeliger L, De Clercq WP, Hoffmann W, Cullis JDS, Horn AM, De Witt M (2018) Applying the water-energy-food nexus to farm profitability in the middle Breede catchment, South Africa. S Afr J Sci 114(11-12):1-10

Simpson GB, Jewitt GPW (2019) The development of the water-energy-food nexus as a framework for achieving resource security: a review. Front Environ Sci 7:8

Stocker TF, Qin D, Plattner M, Tignor SK, Boschung J, Nauels A, Xia Y, Bex V, Midgley PM (2013) Summary for policymakers. Climate change, the physical science basis. Contribution of working group I to the fifth assessment report of the intergovernmental panel on climate change. Cambridge University Press, Cambridge, UK/New York. IPCC-XXVI/Doc.4

Tashtoush FM, Al-Zubari WK, Shah A (2012) A review of the water-energy-food nexus measurement and management approach. Int J Energy Water Resour 3:1-14

UN Water (2013) What is water security. Infographic, 8

United Nation (UN) (2015) Transforming our world: the 2030 agenda for sustainable development resolution adopted by the general assembly. A/RES/70/1 
United Nation (UN) (2020) Report of the secretary-general on the 2019 climate action summit and the way forward in 2020. https://www.un.org/en/climatechange. Accessed June 2020

Volk M (2014) Ecosystem services and river basin models: international conference. In: "Sustainability in the Water-Energy-Food Nexus" C03 Special Session: Ecosystems and their Services in the Nexus, May 19-20, 2014. Bonn

Welsch M, Hermann S, Howells M, Rogner HH, Young C, Ramma I, Bazilian M, Fischer G, Alfstad T, Gielen D (2014) Adding value with CLEWS-modelling the energy system and its interdependencies for Mauritius. Appl Energy 113:1434-1445

World Bank Group (WBG) (2016) Southern Africa energy-water nexus. Report no: ACS19178, World Bank

Open Access This chapter is licensed under the terms of the Creative Commons Attribution 4.0 International License (http://creativecommons.org/licenses/by/4.0/), which permits use, sharing, adaptation, distribution and reproduction in any medium or format, as long as you give appropriate credit to the original author(s) and the source, provide a link to the Creative Commons license and indicate if changes were made.

The images or other third party material in this chapter are included in the chapter's Creative Commons license, unless indicated otherwise in a credit line to the material. If material is not included in the chapter's Creative Commons license and your intended use is not permitted by statutory regulation or exceeds the permitted use, you will need to obtain permission directly from the copyright holder.

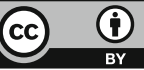

